\title{
Quantitative Trait Loci Affecting Methamphetamine Responses in BXD Recombinant Inbred Mouse Strains
}

\author{
Judith E. Grisel, John K. Belknap, L. A. O’Toole, M. L. Helms, Charlotte D. Wenger, and John C. Crabbe \\ Research Service, Veterans Affairs Medical Center, and Department of Behavioral Neuroscience, Oregon Health Sciences \\ University, Portland, Oregon 97201
}

Individual differences in most behavioral and pharmacological responses to abused drugs are dependent on both genetic and environmental factors. The genetic influences on the complex phenotypes related to drug abuse have been difficult to study using classical genetic analyses. Quantitative trait locus (QTL) mapping is a method that has been used successfully to examine genetic contributions to some of these traits by correlating allelic variation in polymorphic genetic markers of known chromosomal location with variation in drug-response phenotypes. We evaluated several behavioral responses to multiple doses of methamphetamine (METH) in C57BL/6J (B6), DBA/2J (D2), and 25 of their recombinant inbred (BXD RI) strains. Stereotyped chewing, horizontal home cage activity, and changes in body temperature after $0,4,8$, or $16 \mathrm{mg} / \mathrm{kg} \mathrm{METH}$, as well as stereotyped climbing behavior after $16 \mathrm{mg} / \mathrm{kg} \mathrm{METH}$, were examined. Associations $(p<0.01)$ between METH sen- sitivity and allelic status at multiple microsatellite genetic markers were subsequently determined for each response. QTLs were provisionally identified for each phenotype, some unique to a particular behavior and others that appeared to influence multiple phenotypes. Candidate genes suggested by these analyses included several that mapped near genes relevant for the neurotransmitters acetylcholine and glutamate. The locations of QTLs provisionally identified by this analysis were compared with QTLs hypothesized in other studies to influence methamphetamine- and cocaine-related phenotypes. In several instances, QTLs appeared to overlap, which is consistent with idea that common neural substrates underlie some responses to psychostimulants.

Key words: methamphetamine; QTL; quantitative trait locus; recombinant inbred strain; mouse; gene mapping; stereotypy; locomotor activity; body temperature pharmacogenetics
Most responses to drugs of abuse reflect both genetic and environmental influences (Crabbe and Harris, 1991). Furthermore, the genetic influence on drug responses generally results from the collective influences of many genes, each of which may contribute a relatively small amount to the genotypic variance. These quantitative traits have been effectively studied in recombinant inbred (RI) strains of mice. The BXD RI strains [derived by inbreeding novel inbred strains from the $\mathrm{F}_{2}$ cross between C57BL/6J (B6) and DBA/2J (D2) mice] have been the most commonly used in drug abuse research. Under controlled laboratory conditions, phenotypic differences among RI strains largely reflect their genotypic differences: the pattern of B6 and D2 alleles captured in each RI strain is unique because of distinct recombinations of these alleles. Phenotypic strain means can be correlated with allelic status at known genetic markers: a significant relationship indicates a putative quantitative trait locus (QTL) in the same chromosome region as the marker. Each such QTL contains one or more genes that may influence the trait. This approach enables the provisional identification of candidate genes that may influ-

Received July 23, 1996; revised Oct. 22, 1996; accepted Oct. 28, 1996.

These studies were supported by Public Health Service Grants POl AA08621 and P50AA10760, National Institutes of Drug Abuse Contract 271-90-7405, and two grants from the Department of Veterans Affairs. J.E.G. was supported by Training Grant T32 AA07468. A preliminary report of this work has been given at the Specia Conference on The Biology and Genetics of Complex Mammalian Traits, 1995, Bar Harbor, ME. We thank Dr. Steve R. Mitchell for his help with the QTL analyses, Dr. Jeffrey S. Mogil for his suggestions on the preparation of this manuscript, and Dr. Charlie Meshul for his helpful discussions.

Correspondence should be addressed to Judith E. Grisel, Research Service, 151W, Department of Veterans Affairs Medical Center, 3710 SW U.S. Veterans Hospital Road, Portland, OR 97201.

Copyright (C) 1997 Society for Neuroscience $0270-6474 / 97 / 170745-10 \$ 05.00 / 0$ ence a particular behavior or phenotype in the absence of any prior hypotheses about the mechanisms by which such phenotypes are expressed. Furthermore, it is not necessary for the progenitor strains to differ phenotypically; as long as the trait is polygenic (influenced by multiple genes) and variable within the RI panel, QTL analysis can be performed successfully. This might be the case, for instance, if both progenitor strains possess genes for high and low response. Another major strength of this technique is that because inbred strains are genetically stable, all information obtained in these studies is both cumulative and comparable to earlier data, thus providing a rich resource and incentive for collaborative efforts, because genetic correlations can be determined for different measures across different laboratories. Perhaps most important, genes identified in these murine analyses can usually be readily mapped to particular human chromosomal regions because of the high degree of synteny (Copeland et al., 1993). A description of the strategy for QTL mapping has been published previously (Crabbe and Belknap, 1993; Belknap et al., 1996a,b).

Variability in the response to amphetamine in mice is known to depend in part on genetic differences (Kitahama and Valatx, 1979; Crabbe, 1986; DeWit et al., 1986) (for review, see Seale, 1991). Seale et al. (1985) were the first to attempt a systematic genetic analysis of amphetamine sensitivity. Body temperature was measured before and several times after $d$-amphetamine administration in B6, D2, and 10 of their RI derivatives. Later, Gora-Maslak et al. (1991) subjected the Seale et al. (1985) data to QTL analysis and found several promising associations. Although the power of this early experiment to map the responsible genes was limited because only 10 of the RI strains were studied and there were only 
173 polymorphic loci available at the time, it demonstrated the feasibility of locating drug-response genes. Several studies have since used the QTL mapping strategy to locate genes influencing other abused drugs, including those affecting morphine preference (Berettini et al., 1994), alcohol preference (Phillips et al., 1994; Rodriguez et al., 1995; Melo et al., 1996), and alcohol withdrawal (K. Buck, P. Metten, J. Belknap, and J. Crabbe, unpublished observations).

The purpose of the present experiments was to investigate further the genetic substrates of amphetamine-induced responses in mice. Behavioral and physiological responses (stereotyped chewing and climbing, alterations in thermoregulation, and home cage locomotor activity) after administration of $0,4,8$, or 16 $\mathrm{mg} / \mathrm{kg}$ methamphetamine (METH) were evaluated using B6, D2, and 25 of their RI strains. Genetic correlations were calculated between these measures. QTL analysis was performed on these strain means, and QTLs suggested by these experiments were then compared with QTLs hypothesized to influence psychostimulantrelated phenotypes from other studies, including other measures of locomotor activation and stereotypy to amphetamine and cocaine.

\section{MATERIALS AND METHODS}

Animals and drugs. Mice were bred at the Portland VA Veterinary Medical Unit from stock originally obtained from The Jackson Laboratory (Bar Harbor, ME). They were group housed (2-5 animals per cage) at the time of weaning and maintained with ad libitum food and water in a $12 \mathrm{hr}$ light/dark cycle (6:00 A.M. to 6:00 P.M.) at $21 \pm 2^{\circ} \mathrm{C}$. Adult (10-14 week old) mice were used in all studies, and testing was conducted between 8:00 A.M. and 12:00 P.M. (see below). Animals in each experiment were tested over several weeks, with strains roughly counterbalanced across the experimental period. Each mouse was tested once, but each strain was tested at multiple times. On test days, cages of mice were transported to the testing room and mice were weighed 45-60 min before the start of the test session and then randomly assigned to either the METH or the saline (SAL) group, with multiple doses represented in each cage. Animals were given either SAL or METH $(4,8$, or $16 \mathrm{mg} / \mathrm{kg}$, i.p.; $0.8,1.2$, or $1.6 \mathrm{mg} / \mathrm{ml}$ in a volume of $0.01 \mathrm{ml} / \mathrm{gm}$ body weight; Sigma, St. Louis MO) and tested as described below.

The development of the BXD RI strains has been described previously (Taylor, 1978). Briefly, inbreeding from the $\mathrm{F}_{2}$ generation of $\mathrm{B} 6 \times \mathrm{D} 2$ crosses has resulted in 26 viable strains that show unique recombinations of B6 and D2 alleles: on average, three to four crossovers per chromosome have been preserved in each RI strain. All members of each RI strain are homozygous for either the B6 or the D2 allele at each locus. Twenty-five RI strains were available in sufficient number for testing in Experiment 1, and 24 strains for Experiment 2. All procedures were approved by the VA Institutional Animal Care and Use Committee and performed in accordance with National Institutes of Health guidelines for the care and use of animals in research.

\section{Experiment 1}

Assessment of stereotyped chewing, home cage locomotor activity, and temperature changes induced by METH. One of the primary aims of this study was to characterize the alterations in thermoregulation after METH administration in the BXD mice. Pilot studies had determined that repeated temperature assessment in B6 and D2 mice (using a rectal probe) resulted in lower temperatures than a single temperature determination at a comparable time point. Further, this effect was largely strain-dependent. To circumvent any confounds caused by repeated testing, we used only a single temperature measurement per mouse. We also chose to use behavioral measures that involved neither handling of animals nor novel environments and, thus, they were unlikely to affect body temperature determinations. These observational measures were exophthalmos (eye protrusion), chewing, and home cage horizontal activity. The analyses of these behaviors were conducted in 862 male mice of $25 \mathrm{RI}$ strains and both progenitor strains. The $N$ per strain per dose was 8 in almost all cases. The measurement of exophthalmos proved to be unreliable (reflected in a nonsignificant split-half reliability estimate of $r=0.36$ ) and, thus, genetic influences on this phenotype could not be evaluated. Therefore, the observation of exophthalmos in these mice was excluded from our analysis and will be omitted from the following discussion.

Each animal was taken from its home cage, weighed, injected with either SAL or METH $(4,8$, or $16 \mathrm{mg} / \mathrm{kg})$, and returned to its home cage with its normal cagemates. Only one mouse at a time in each cage was injected per experimental session, with four sessions per day. Starting 17 min after injection, activity was assessed for $1 \mathrm{~min}$ as the number of quadrant crossings in the home cage (each time an injected mouse entered a different quarter of the cage, 1 activity count was scored). Thirty-three minutes after injection, the injected subjects were again assessed for the number of chewing or gnawing occurrences for the next minute. Repetitive chewing involved paw-to-mouth movements most often directed at the corn cob bedding material, although frequently $(\sim 25 \%$ of the time) it did not involve any object. Although food was present, it was never seen to be the object of chewing. Forty-eight minutes after injection, body temperature was determined with a rectal probe inserted $2 \mathrm{~cm}$ using an analog thermometer.

Measurement of brain METH concentration. Brain METH levels were determined by gas chromatography from samples taken immediately after the test for mice given either 4 or $8 \mathrm{mg} / \mathrm{kg}$ METH. Brains were excised and homogenized in $0.1 \mathrm{M}$ potassium phosphate buffer, $\mathrm{pH} 6.0$. A $550 \mathrm{ml}$ aliquot was centrifuged at $13,000 \mathrm{rpm}$ for $10 \mathrm{~min}$, and $400 \mathrm{ml}$ of the supernatant was transferred to a new tube. Internal standard and $600 \mathrm{ml}$ of fresh buffer were added. The sample prep columns (Bond-Elut, $3 \mathrm{cc}$ ) were washed through the column, and the column was aspirated for 5 min. Next, $5 \mathrm{ml}$ of methanol was washed through and the column was dried for $3 \mathrm{~min}$. Finally, $1.5 \mathrm{ml}$ of freshly prepared $2 \%$ ammonium hydroxide in ethyl acetate was slowly passed through the column and collected. A $500 \mathrm{ml}$ portion of this material was placed in a glass vial along with $50 \mathrm{ml}$ of $1 \% \mathrm{HCl}$ in methanol, and the solution was dried. This was continued until all of the sample was dried. Next, $60 \mathrm{ml}$ of heptafluorobutyl anhydride was added and the vial was sealed and heated at $70^{\circ} \mathrm{C}$ for $20 \mathrm{~min}$. The vial was then cooled and dried, and $400 \mathrm{ml}$ of ethyl acetate was added. The sample was sealed and vortexed, and $1 \mathrm{ml}$ was injected in the GC/MS for analysis following the methods of Foltz et al. (1990).

\section{Experiment 2}

Assessment of stereotyped climbing induced by METH. In rodents, low doses of amphetamine $(0.25-1.0 \mathrm{mg} / \mathrm{kg})$ produce hypothermia and a general activation comprised of sniffing, locomotion, and rearing. Higher doses result in hyperthermia and a decreasing incidence of competing behaviors, as stereotyped behaviors begin to emerge (Randrup and Munkvad, 1967; Jellinek, 1971). Stereotypy may take many forms that depend in part on the animal species, dose of amphetamine, and time after injection, as well as environmental factors such as stress or previous pharmacological history with psychostimulants (Randrup et al., 1975). Rapid and repetitious paw-to-mouth movements (chewing) have been the most frequently studied behavior in rodents.

Protais et al. (1976) initially characterized and standardized climbing behavior as a stereotypy elicited by dopamine agonists in mice. After apomorphine administration, mice show increased locomotor activity and, if placed in a cage with mesh walls, enhanced climbing behavior (see, for example, Marcais et al., 1978; Balsara et al., 1981; Joshi et al., 1981; Cabib et al., 1995). A pilot study assessing the effects of several doses of METH determined that $16 \mathrm{mg} / \mathrm{kg}$ produced the most robust climbing response in both $\mathrm{B} 6$ and $\mathrm{D} 2$ mice. Therefore, 715 adult female mice from 24 of the BXD/Ty RI set-in addition to B6 and D2 mice-were tested on the climbing apparatus after intraperitoneal injection of either equivolume SAL or $16 \mathrm{mg} / \mathrm{kg}$ METH. Immediately after the injection, mice were placed in a single cage on corncob bedding surrounded by a $12-\mathrm{cm}$-diameter wire mesh chimney $24 \mathrm{~cm}$ high, constructed from 0.5 inch hardware cloth. The top of each chimney was covered to prevent escape. Animals were scored during a single $2 \mathrm{sec}$ inspection each $5 \mathrm{~min}$ throughout a $60 \mathrm{~min}$ test period as follows (Protais, 1976): 4 paws on the floor (0), forefeet on the wall or grooming [i.e., 2 feet on floor (1)], 4 paws on the wall [climbing (2)].

Data analysis. Mean SAL strain values were subtracted from individual post-METH scores to obtain a measure of the METH-induced change in each behavior for Experiment 1. The effects of strain on METH sensitivity were then analyzed by one-way ANOVA at each dose for Experiment I. A single-factor (strain) ANOVA was also used to examine climbing in the RIs and their progenitors after $16 \mathrm{mg} / \mathrm{kg} \mathrm{METH}$ in Experiment 2. Climbing scores were averaged over $15 \mathrm{~min}$ time periods to create four epochs. Because strains also differed in climbing behavior 
after SAL, METH sensitivity was again determined by subtracting each strain's mean saline score for the corresponding time period from the individual post-METH scores within a strain. To determine the reliability of the measures assessed in these studies, split-half correlations were obtained for each trait and corrected using the Spearman-Brown method. Genetic correlations (i.e., among strain means) were estimated among the dependent measures examined in this study (Hegmann and Possidente, 1981).

QTL analysis. Over 1500 genetic markers (Mammalian Genome, 1996) have been genotyped in the BXD RI strains, mostly comprising microsatellite simple sequence repeat polymorphisms determined by PCR, so that the location and the B6- or D2-like repeat length of each of these alleles is known for each strain. By convention, D2 alleles are coded with values of 1 , and B6 alleles with values of 0 in our database. Therefore, to identify the putative location of relevant QTLs, the strain mean values for chewing, body temperature, home cage activity, and climbing were correlated with the value ( 0 or 1$)$ at each of the polymorphic loci in our data set. For body temperature changes and activity, each of the three doses was considered as a separate trait for QTL analysis. Thus, a total of eight behavioral traits were analyzed. A statistically significant correlation at $p \leq 0.01$ between the phenotype and the allelic state at a particular marker indicates that a gene in this region of the genome may influence the response to METH. A significant clustering of markers showing similar correlations on a particular region of the genome is more likely to point to a true locus of influence. Even so, primarily because of the large number of correlations calculated, there is a high probability of false positives. However, making the criteria more stringent would increase the likelihood of type II errors or false negatives (missing actual influential loci). Our strategy, therefore, is to use this analysis as an initial screen, suggesting provisional regions of influence that await confirmation or rejection in subsequent analyses. Our general approach for subsequent verification of the QTLs provisionally reported here has been discussed previously (Belknap et al., 1993, 1996a,b; Crabbe et al., 1994) (K. Buck, P. Metten, J. Belknap, and J. Crabbe, unpublished observations). We plan to examine other populations to follow up the results reported here with the goal of attaining aggregate levels of statistical significance required to accept linkage that have been proposed by Lander and Kruglyak (1995).

\section{RESULTS}

\section{Dose-effect analysis in several METH-induced behaviors}

Significant dose-related effects of METH on all responses assessed were evident (data not shown). Repetitive chewing showed a roughly linear dose-response function; the $16 \mathrm{mg} / \mathrm{kg}$ dose resulted in near $100 \%$ frequency for chewing for almost all strains. In contrast, body temperature and home cage activity responses evidenced biphasic curves. The lowest dose of METH, $4 \mathrm{mg} / \mathrm{kg}$, caused statistically significant hypothermia, whereas the highest dose, $16 \mathrm{mg} / \mathrm{kg}$, caused significant hyperthermia. Similarly, 4 $\mathrm{mg} / \mathrm{kg} \mathrm{METH}$ resulted in peak locomotor activation, whereas higher doses showed progressive decreases in home cage activity.

Strains differed widely with respect to METH-induced effects. For instance, B6 mice showed no effect of METH on body temperature at any dose, whereas others (such as BXD-1) showed consistent hyperthermia at all doses (consistent with Seale et al., 1986). Figure 1 shows the METH-induced (METH - mean SAL) body temperature changes in all 27 strains at each of the three doses. At the $4 \mathrm{mg} / \mathrm{kg}$ dose (top panel), there was wide variation in body temperature changes $\left(F_{(26,185)}=5.31, p<0.0001\right)$. Eight strains showed significant hypothermia, and two were hyperthermic relative to saline control values. At the highest dose (16 $\mathrm{mg} / \mathrm{kg}$; bottom panel), there were also differences among strains $\left(F_{(26,188)}=3.55, p<0.0001\right)$ : none of the strains were hypothermic, and $\sim 75 \%$ showed significant hyperthermia. The $8 \mathrm{mg} / \mathrm{kg}$ dose (middle panel) was intermediate but also variable $\left(F_{(26,190)}=\right.$ $6.25, p<0.0001)$. Overall, METH-induced body temperature changes were quite heritable, with genotype (strain) accounting
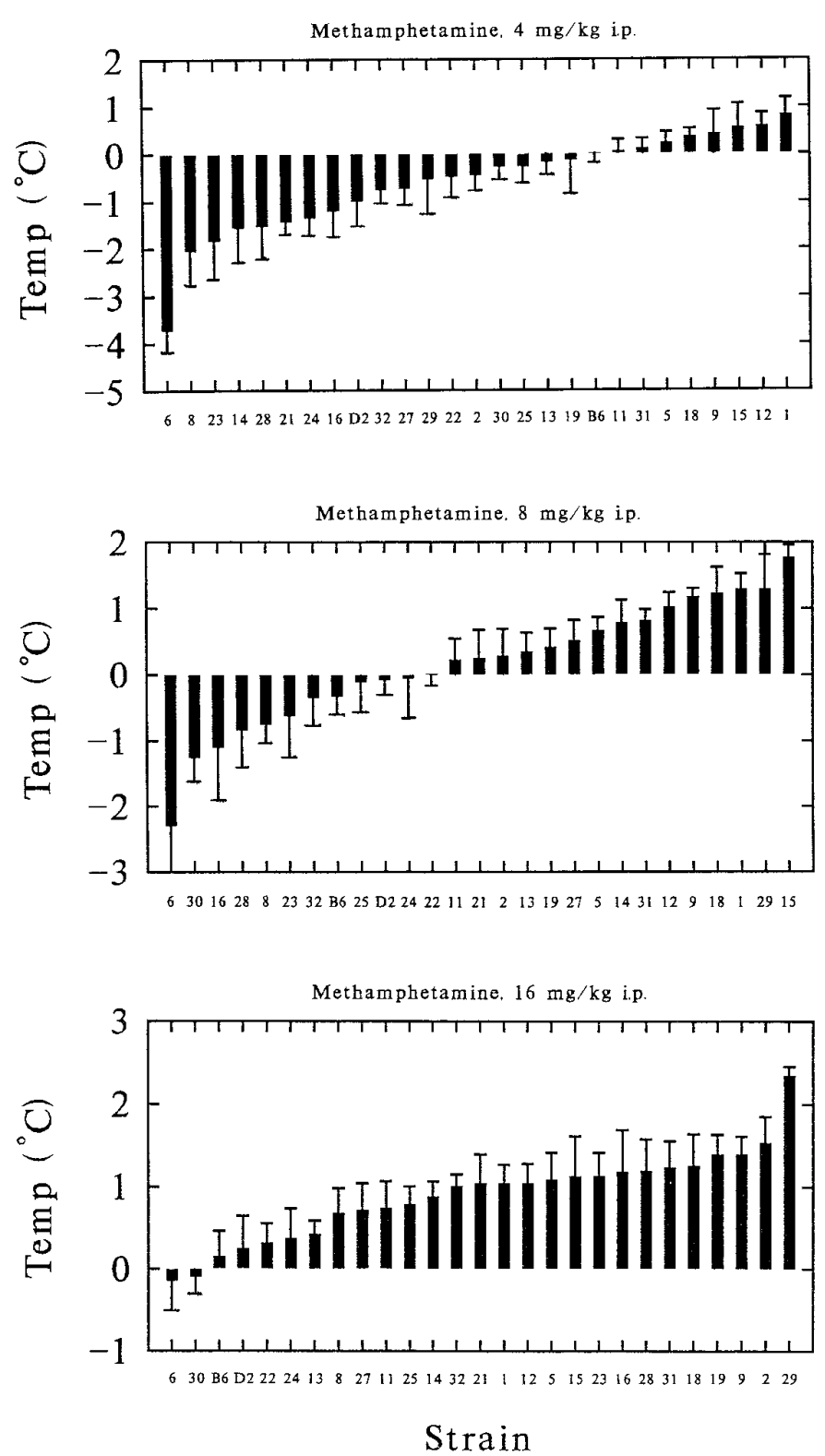

Figure 1. Changes in body temperature in 25 BXD RI strains and the two progenitor strains after $4 \mathrm{mg} / \mathrm{kg}$ (top), $8 \mathrm{mg} / \mathrm{kg}$ (middle), or $16 \mathrm{mg} / \mathrm{kg}$ (bottom) intraperitoneal METH injection. The strains are plotted in order from the most negative response (hypothermia) on the left to the most positive response (hyperthermia) on the right. Each bar shows the mean \pm SEM for each dose. The strains along the $x$-axis refer to the BXD strain number; B6 and D2 mice are also labeled.

for 43,46 , and $33 \%$ of the total observed variance $\left(R^{2}\right)$ at the 4,8 , and $16 \mathrm{mg} / \mathrm{kg}$ doses, respectively.

The typical dose-response curve with respect to home cage activity is an inverted U-shaped function. The individual strain means for home cage horizontal activity after the three doses of METH are shown in Figure 2. The $4 \mathrm{mg} / \mathrm{kg}$ dose (top panel) induced more activation than the other doses and varied significantly among strains $\left(F_{(26,186)}=4.37, p<0.0001\right)$. All strains were significantly activated by this dose of METH except for BXD-8 mice. Increases in home cage locomotor activity were also commonly observed after $8 \mathrm{mg} / \mathrm{kg} \mathrm{METH}$ and, again, they differed significantly among strains $\left(F_{(26,190)}=6.73, p<0.0001\right.$; middle panel). In contrast, the $16 \mathrm{mg} / \mathrm{kg}$ dose (bottom panel) 

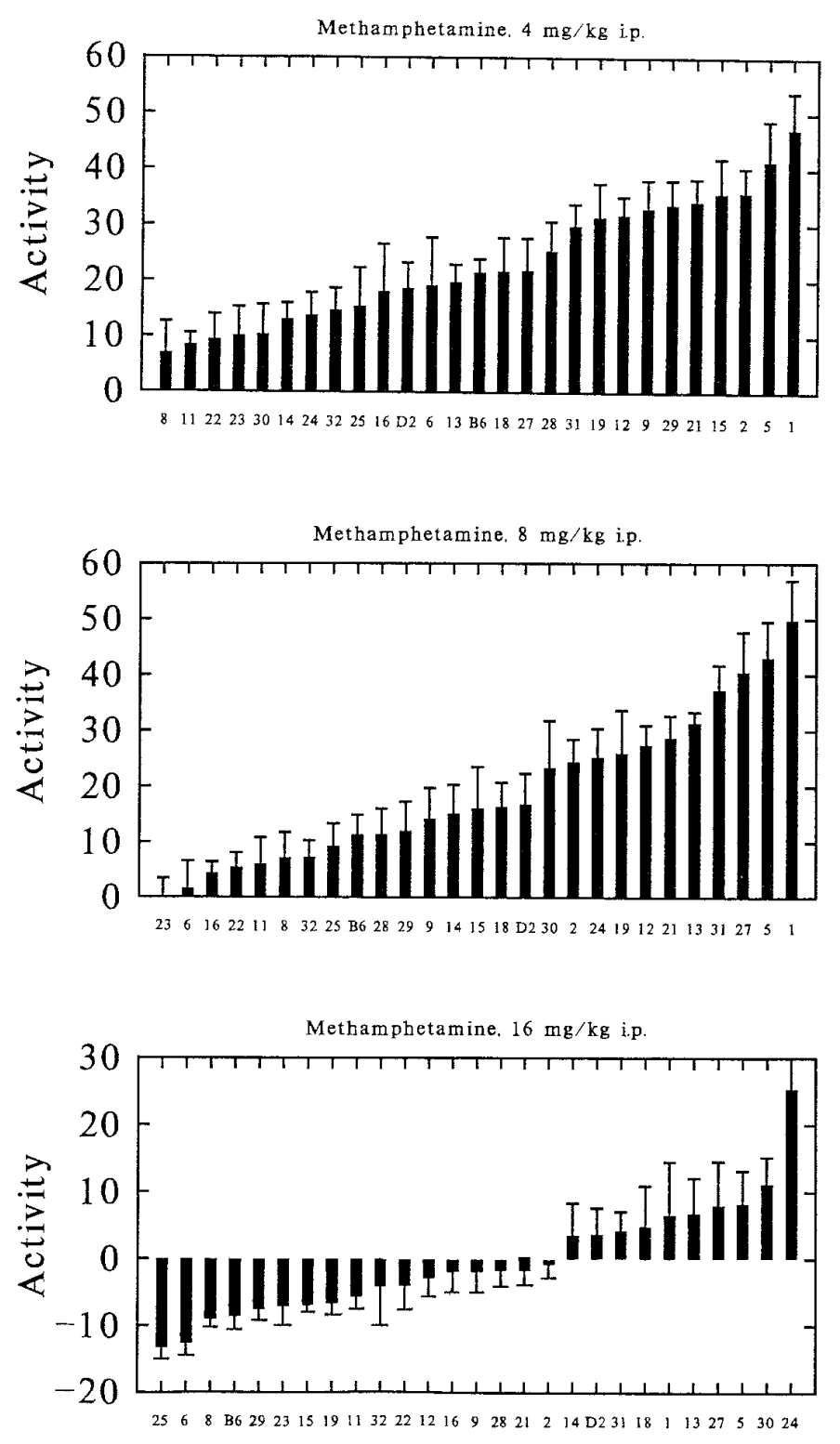

Strain

Figure 2. Mean \pm SEM number of quadrant crossings $/$ min (home cage activity) for B6, D2, and 25 BXD RI strains after $4 \mathrm{mg} / \mathrm{kg}$ (top), $8 \mathrm{mg} / \mathrm{kg}$ (middle), or $16 \mathrm{mg} / \mathrm{kg}$ (bottom) intraperitoneal METH. See legend to Figure 1.

produced significant reductions in activity in nine strains and enhanced activity in only two strains $\left(F_{(26,188)}=34.98, p<\right.$ 0.0001). Again, METH-induced home cage activity was quite heritable, with genotype accounting for 38,48 , and $41 \%$ of the total variance for the 4,8 , and $16 \mathrm{mg} / \mathrm{kg}$ doses, respectively.

Repetitive chewing was almost never seen in animals treated with the $4 \mathrm{mg} / \mathrm{kg}$ dose of METH, whereas chewing was near maximal in most strains after the $16 \mathrm{mg} / \mathrm{kg}$ dose (data not shown). Thus, only the $8 \mathrm{mg} / \mathrm{kg}$ dose was particularly useful in assessing strain differences in sensitivity to this behavior (Fig. 3). As in the other behaviors, repetitive chewing showed large strain differences, from no response in three strains to continuous chewing throughout the observation period in three other strains $\left(F_{(26,190)}\right.$ $=3.51, p<0.0001)$. Genotype accounted for $33 \%$ of the total

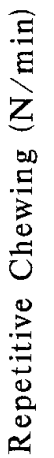

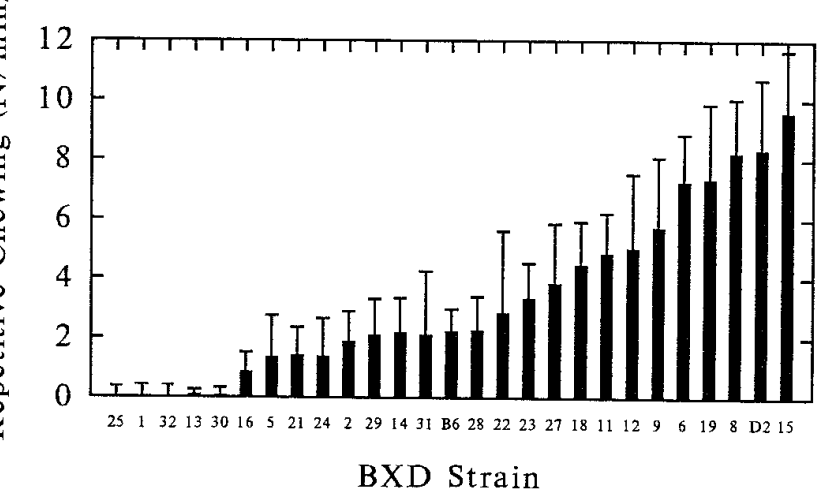

Figure 3. BXD RI strain chewing responses (mean \pm SEM) after 8 $\mathrm{mg} / \mathrm{kg}$ METH. See legend to Figure 1.

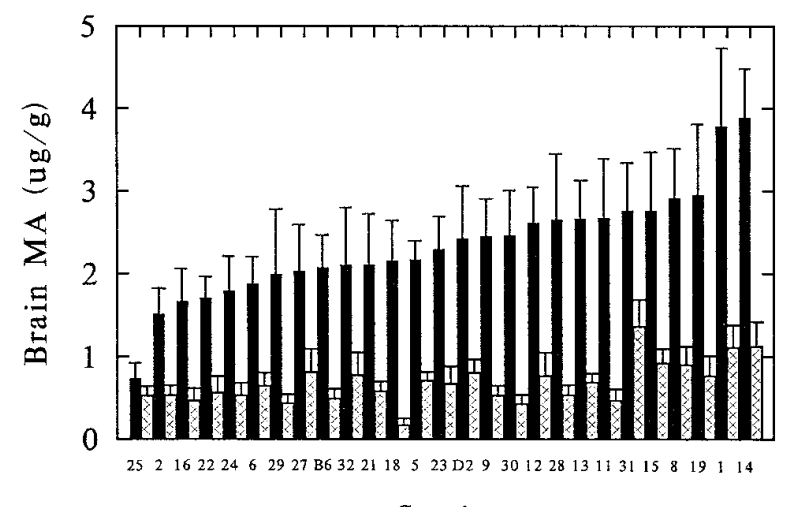

Strain

Figure 4. Brain METH levels $(\mu \mathrm{g} / \mathrm{gm})$ after $4 \mathrm{mg} / \mathrm{kg}$ (hatched bars) or 8 $\mathrm{mg} / \mathrm{kg}$ (solid bars) METH in B6, D2, and 25 BXD RI strains. See legend to Figure 1.

observed variance at this dose. Stereotypy was also measured by examining the climbing response in Experiment 2.

Spearman-Brown-corrected split-half reliability estimates indicated that all of these measures were reliable. For the temperature changes $r_{\mathrm{SB}}=0.81,0.76$, and 0.78 after 4,8 , and $16 \mathrm{mg} / \mathrm{kg}$, respectively. Activity changes were also reliable: $r_{\mathrm{SB}}=0.75,0.87$, and 0.86 at the same doses. Finally, the corrected reliability estimate for chewing was $r_{\mathrm{SB}}=0.85$.

\section{Brain METH concentrations}

Although brain METH levels did vary significantly among strains at the $4 \mathrm{mg} / \mathrm{kg}$ dose $\left(F_{26,183}=1.724, p<0.05\right)$, no significant differences in brain METH levels were evident after $8 \mathrm{mg} / \mathrm{kg}$ METH $(p>0.10)$ (Fig. 4). The correlation between the strain means for brain METH concentrations after these two doses was $0.61(p<0.001)$. However, brain concentrations of METH were not significantly correlated with any of the METH sensitivity measures taken in these same animals. Thus, because pharmacokinetic differences did not account for genotypic differences in drug response, we did not correct for brain METH concentrations when evaluating the effects of METH.

\section{Effect of $16 \mathrm{mg} / \mathrm{kg}$ METH on stereotyped climbing in BXD RIs}

As with D2 mice, in many of the RI strains there was little evidence of stimulation during the initial $15 \mathrm{~min}$ period after injection. That is, for most RI strains, METH-treated groups did 


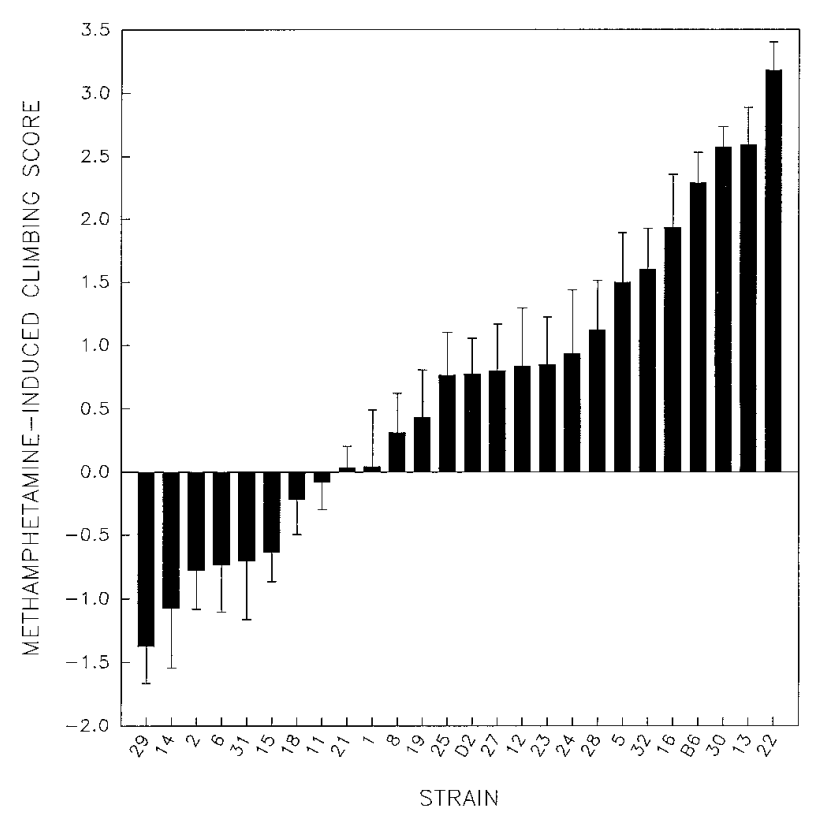

Figure 5. Total METH-induced climbing scores $( \pm$ SEM) for all BXD RI strains for the period from 15 to $60 \mathrm{~min}$ after $16 \mathrm{mg} / \mathrm{kg}$ METH. See legend to Figure 1.

not differ initially from the SAL group and, therefore, data from the first epoch were excluded from further analysis. An initial analysis considered strain differences in SAL treatment across the latter three epochs using a two-way ANOVA. Baseline (SAL) scores were significantly variable across strains $\left(F_{25,328}=4.66\right.$, $p<0.0001)$, although SAL climbing did not vary across epochs $\left(F_{2,656}=0.449, p=0.64\right)$ and the effect of strain did not depend on the time epoch examined $\left(F_{50,656}=0.92, p=0.63\right)$. Therefore, data at each time point were indexed as the mean difference score of all the individual METH scores within a strain from the mean SAL score.

Because the strain-specific response to METH was highly correlated across epochs, a total climbing score was calculated. Figure 5 shows that there was also wide variation within the BXD panel for the combined METH-induced difference scores $\left(F_{25,334}\right.$ $=13.52, p<0.0001)$. Twelve strains responded with stimulated climbing, whereas six others showed decreased climbing and the remaining eight strains did not significantly alter their climbing activity after METH administration. The Spearman-Browncorrected reliability estimate for the climbing change after 16 $\mathrm{mg} / \mathrm{kg}$ METH was 0.79 .

\section{Genetic correlations among responses to METH}

Table 1 shows correlations among strain responses to METH. Because they were based on strain means, they are predominantly genetic in origin (Hegmann and Possidente, 1981). Within the temperature and home cage activity measures, there was evidence for a high degree of genetic control in common across doses. For activity, the 4 and $8 \mathrm{mg} / \mathrm{kg}$ doses correlated $r=0.77$, and the 8 and $16 \mathrm{mg} / \mathrm{kg}$ doses correlated $r=0.49$. Similarly, temperature correlations across doses ranged from 0.49 to 0.84 . The strains most activated by 4 or $8 \mathrm{mg} / \mathrm{kg}$ METH had greater increases (or lesser decreases) in METH-induced body temperature induced by all three doses. This suggests that some genes affect both thermal and locomotor responses to METH. The other behavioral responses were not generally correlated with each other, indicating that they are largely subserved by different mechanisms and/or neural substrates. An exception to this generalization was the significant genetic correlation between hyperthermia and climbing $(r=-0.44)$ at the $16 \mathrm{mg} / \mathrm{kg}$ dose. Interestingly, the two measures thought to index forms of stereotyped behavior, chewing and climbing, tended to correlate negatively $(r=-0.32$, not significant), suggesting that chewing and climbing may be competitive behaviors.

In contrast to all other measures, climbing was evaluated in female mice (both genders were not evaluated for all phenotypes because of the limited availability of these strains). It is possible, therefore, that some of the putative common loci may in fact be gender-specific and that these correlations would change if one sex were examined for all measures. Combining data from mice of both sexes is perhaps most likely to result in an underestimation of common genetic etiology; furthermore, in pilot studies examining METH-induced climbing in both female and male B6 and D2 mice, strain differences did not depend on gender. Therefore, although it is certainly important to note this difference between the measures in Table 1, gender effects are unlikely to have a large impact on our interpretation of the data.

\section{QTL analysis of METH sensitivity}

To identify the putative location of relevant QTLs, the strain mean values for chewing, home cage activity, body temperature, and climbing were correlated with the value ( 0 or 1$)$ at each of the polymorphic loci in our database. Multiple QTLs were provisionally identified ( $p \leq 0.01$; Table 2 ) for each measure of drug sensitivity. In several instances, possible candidate genes map to nearby locations. For each chromosome region, only the marker showing the highest correlation with each drug sensitivity measure is shown, but a list of all significant associations is available from the authors. The locations of provisionally mapped QTLs are shown schematically in Figure 6.

\section{DISCUSSION}

Genetic factors mediate some of the variability between individuals in response to psychostimulants (c.f. Broadhurst, 1978; Seale, 1991). We have analyzed several responses to METH in the BXD RIs and their progenitors in order to identify putative genetic loci contributing to METH sensitivity. A comparison of the pattern of METH-induced strain mean effects with polymorphic genetic markers resulted in the identification of $>70$ provisional loci over all eight traits, or about eight to nine per trait. These can be used to generate hypotheses about candidate genes as well as to focus future testing in other genetic models. The next phase of the analysis will be to determine which of these provisional loci represent actual associations with high probability (Lander and Kruglyak, 1995). Computer simulations (Belknap et al., 1996a,b) and our experience (K. J. Buck, P. Metten, J. K. Belknap, and J. C. Crabbe, unpublished observations) suggest that approximately half of these loci will prove to represent true associations.

\section{Candidate neurotransmitter modulation}

Extensive pharmacological and neuroanatomical evidence that has been accumulating since the 1970 s makes a strong case for the role of dopamine in psychostimulant-produced behaviors (see, for example, Groves and Rebec, 1976; Kuczenski, 1986; Hernandez et al., 1987). Congruent with these hypotheses, both temperature and activity changes induced by METH were associated with a region on chromosome 7 near the dopamine D4 receptor gene (Drd4). Locomotor activation in response to $4 \mathrm{mg} / \mathrm{kg} \mathrm{METH}$ was 


\begin{tabular}{|c|c|c|c|c|c|c|c|}
\hline & Activity (4) & Activity (8) & Activity (16) & Temp change (4) & Temp change $(8)$ & Temp change (16) & Chewing (8) \\
\hline \multicolumn{8}{|l|}{ Activity (4 mg/kg) } \\
\hline Activity (8) & $+0.77 * *$ & & & & & & \\
\hline Activity (16) & +0.08 & $+0.49 * *$ & & & & & \\
\hline Temp change (4) & $+0.51^{* *}$ & $+0.54^{* *}$ & +0.11 & & & & \\
\hline Temp change (8) & $+0.57 * *$ & $+0.53^{* *}$ & +0.16 & $+0.84^{* *}$ & & & \\
\hline Temp change (16) & $+0.45^{*}$ & +0.13 & -0.17 & $+0.49^{*}$ & $+0.67^{* *}$ & & \\
\hline Chewing (8) & -0.03 & -0.16 & -0.34 & -0.13 & +0.05 & +0.12 & \\
\hline Climbing (16) & -0.29 & -0.11 & +0.13 & +0.15 & -0.30 & $-0.44^{*}$ & -0.31 \\
\hline
\end{tabular}

also associated with a region on chromosome 16 that contains the gene for both the D3 receptor and the enzyme catechol- $O$ methlyltransferase (Comt), which is important for the catabolism of catecholamines. Even though genes for several dopamine receptor subtypes and the dopamine transporter have been mapped in mice, it is perhaps noteworthy that no QTLs suggested by analyses of either stereotyped behavior were found in the vicinity of these or other known dopamine-related genes. This finding does not necessarily imply that dopamine neurotransmission is not involved in METH-induced stereotypy but, rather, that genetic variability in dopamine activity in the BXD RIs may not underlie genetic differences in METH-induced stereotypy (as measured in the present studies). There is a dissociation between dopamine activation in the striatum induced by psychostimulants, and behavioral stereotypy, because there does not appear to be a strict temporal correlation between the amount of dopamine release in either the caudate nucleus or the nucleus accumbens with the stereotypic stimulation observed (Kuczenski et al., 1989, 1990, 1991). Our data are congruent with this interpretation and go further to suggest that the genetic variability in the chewing and climbing stereotypical responses depend more on other neural substrates which may, in turn, interact with dopamine mechanisms.

For instance, there is compelling evidence for modulation of METH-stimulated behaviors by acetylcholine and glutamate, neurotransmitters for which loci associated with relevant genes were identified in our analysis. Some of these areas are particularly attractive loci for attempts at verification because they overlap between studies of related phenotypes. For example, QTLs on mid-chromosome 1 , associated with climbing, home cage activity, and temperature changes, are in a region where QTLs were provisionally mapped for open-field locomotor stimulation (horizontal movement) after 1 and $2 \mathrm{mg} / \mathrm{kg} \mathrm{METH}$ and its sensitization (T. J. Phillips, M. Huson, C. Gwiazdon, and C. McKinnon, unpublished observations); this region contains genes coding for both the $\delta$ and the $\gamma$ subunits of the nicotinic acetylcholine receptor. Moreover, a region on chromosome 9 that appears to be associated with the activity and temperature changes after METH in the present studies-also identified by the Phillips group as associated with cocaine-induced locomotor stimulation and METH sensitization-contains the gene for the $a_{3}$ subunit of the acetylcholine receptor. The gene coding for the $\mathrm{a}_{2}$ subunit is in a region on proximal chromosome 14 with markers associated with a cluster of METH-related phenotypes (discussed below). There is also substantial biochemical and histochemical evidence suggesting that B6 and D2 mice differ with respect to cholinergic activity (Ebel et al., 1973; Durkin et al., 1977) and cell density
(Albanese et al., 1985; Iacopino et al., 1986; Schwab et al., 1990). Furthermore, the genetic variability in cholinergic cell number in the striatum was shown by Dains (1995) to be correlated with neuroleptic-induced catalepsy in the mouse, suggesting an interaction between acetylcholine and dopamine in the production of striatally mediated motor behavior. Although the relationship between striatal dopamine and acetylcholine has been well documented (Graybiel, 1990; Florin et al., 1992; Groves et al., 1995), the joint dopamine/acetylcholine responses to amphetamine do not appear to be sufficient to explain the behavioral changes observed, implying likely interactions with still other neurotransmitter systems (Kuczenski et al., 1977).

It is clear also that both glutamate and GABA are also involved in the locomotor activation resulting from dopamine agonist administration (Balsara et al., 1981; Liljequist and Karcz-Kubicha, 1993; Karler et al., 1995). For example, Karler et al. (1994, 1995) found that pharmacological blockade of dopamine, glutamate, or GABA receptors in the ventral lateral striatum could prevent the stereotypy induced by amphetamine or cocaine. The dopaminergic projections from the substantia nigra pars compacta are known to involve both of these other transmitters in the striatal-thalamic-cortical loop thought to underlie the locomotor activating effects of psychostimulants. Our data suggest that glutamate modulation by the enzyme glutamate dehydrogenase may play a role in determining individual differences in genetic sensitivity to activation by amphetamine, because variation in a marker near the Glud locus (and the acetylcholine $\mathrm{a}_{2}$ subunit) on chromosome 14 was correlated with genetic variability in four observed traits (climbing and body temperature changes after $16 \mathrm{mg} / \mathrm{kg} \mathrm{METH}$ and home cage activity after either 8 or $16 \mathrm{mg} / \mathrm{kg} \mathrm{METH})$. Given the consensus among genetic studies and the behavioral data suggesting a role for glutamate in responsivity to psychostimulants, further testing of this locus in an $\mathrm{F}_{2}$ intercross might be a fruitful endeavor.

\section{QTLs affecting multiple phenotypes}

There are three other published genetic analyses of psychostimulant responses in the BXD RIs. Data collected by Seale et al. (1985) were subject to QTL analyses by Gora-Maslak et al. in 1991. The hyperthermia induced by $20 \mathrm{mg} / \mathrm{kg}$ amphetamine was found to be associated with markers in four distinct regions of the mouse genome. These were from 10 RI strains and a very limited set of less than 200 markers, constraints that would imply that any associations observed would be likely to reflect fairly large genetic influences but would also have a higher probability of being spurious. In fact, all four of these regions overlap with those suggested for some traits by the current analyses, although we 
Table 2. Genetic markers, chromosome number, distance from centromere in cM (e.g., 1:8.7), and associations with METH responses for home cage activity, body temperature, chewing, and climbing

\begin{tabular}{|c|c|c|c|c|c|c|}
\hline Marker & Location & $\begin{array}{l}\text { HC activity } \\
\text { (dose) }\end{array}$ & $\begin{array}{l}\mathrm{T}^{\circ} \text { change } \\
(\text { dose })\end{array}$ & $\begin{array}{l}\text { Chewing } \\
(8 \mathrm{mg} / \mathrm{kg})\end{array}$ & $\begin{array}{l}\text { Climbing } \\
(16 \mathrm{mg} / \mathrm{kg})\end{array}$ & Candidate \\
\hline D1Mit1 & $1: 8.7$ & $-0.66[16]$ & & & & \\
\hline D1Ncvs 75 & $1: 41$ & & $-0.52[16]$ & & & \\
\hline D1Ncvs 41 & $1: 48.4$ & $-0.68[4]$ & $-0.68[8]$ & & +0.65 & Acrg/Acrd (52.3) \\
\hline D1Ncvs12 & $1: 74.5$ & & & & +0.68 & \\
\hline D1Ncvs59 & 1:107 & & $-0.54[4]$ & & & \\
\hline Brp13 & $2: 25$ & & & & +0.67 & \\
\hline Hoxd & $2: 35$ & & & -0.55 & & \\
\hline$D 2 M c 1$ & $2: 83$ & & & & -0.62 & \\
\hline Evil & $3: 14.4$ & $+0.52[4]$ & & & & \\
\hline$I l 2$ & $3: 19.2$ & $+0.52[8]$ & & & & \\
\hline Gnat2 & $3: 49$ & & $-0.56[16]$ & & & \\
\hline P40-rs4 & $3: 79.6$ & & $+0.53[4]$ & & & \\
\hline Mltr3 & $4: 16.8$ & & & & +0.50 & \\
\hline$L y b 4$ & $4: 24.8$ & & & -0.55 & & \\
\hline$D 4 N d s 8$ & $4: 20.7$ & & $-0.50[16]$ & & & \\
\hline Ms6hm & $4: 40.3$ & & & & +0.52 & \\
\hline Sac & $4: 83$ & & & & +0.66 & \\
\hline D5Ncvs56 & $5: 14$ & $+0.55[8]$ & & & & \\
\hline D5Rik85 & $5: 26$ & & & & +0.51 & \\
\hline D5Mit10 & $5: 54$ & & & -0.76 & & \\
\hline D5Вуи 4 & $5: 68$ & & & & +0.59 & \\
\hline Ache & $5: 81$ & & & & +0.55 & Ache (81.0) \\
\hline Met & $6: 6$ & $-\mathbf{0 . 6 6}[4]$ & & & & \\
\hline D6Ncvs34 & $6: 27$ & & $-0.51[8]$ & & & \\
\hline D6Nds3 & $6: 31$ & $-\mathbf{0 . 6 6}[4]$ & & & & \\
\hline D6MIt16 & $6: 31$ & & $-0.59[16]$ & & & \\
\hline$D 6 N d s 2$ & $6: 40$ & & $+0.52[8]$ & & & \\
\hline II5ra & $6: 47$ & $+0.57[8]$ & & & & \\
\hline$N m d a r 2 b$ & $6: 65$ & & $+0.57[4] /+0.53[8]$ & & & \\
\hline D7Mit12 & $7: 66$ & $+\mathbf{0 . 6 8}[4] /+0.59[8]$ & & & & \\
\hline$X m v 76$ & $7: 73$ & & $+0.58[4] /+0.56[8] /+0.58[16]$ & & & $\operatorname{Drd4}(70.3)$ \\
\hline D8Bir2 & $8: 13$ & $0.55[4]$ & & & +0.59 & Adrb3 (10.0) \\
\hline D8Ncvs 43 & $8: 45$ & & $-0.52[16]$ & & & \\
\hline Fli-1 & $9: 16$ & $-\mathbf{0 . 6 8}[8]$ & & & & \\
\hline Gst2-3 & $9: 47.5$ & $-0.58[16]$ & & & & \\
\hline D9Mit12 & 9:55 & & $-0.61[16]$ & & & Acra3 (51.0) \\
\hline D9Ncvs17 & $9: 65$ & $-0.54[8]$ & & & & \\
\hline Cck & 9:71 & & $-\mathbf{0 . 6 7}[8]$ & & & \\
\hline D9Вуиб & $9: 71$ & & $-\mathbf{0 . 6 7}[4]$ & & & \\
\hline Tel9q & 9:74 & & & -0.58 & & \\
\hline D10Mit144 & $10: 54$ & $-0.55[16]$ & & & & \\
\hline Kcnc2 2 & $10: 62$ & & $-0.51[4]$ & & & \\
\hline Mox2 & $12: 20$ & & $+0.54[16]$ & & & \\
\hline$X m m v 50$ & $12: 55$ & $+0.59[4]$ & $+0.58[4] /+0.56[8] /+0.58[16]$ & & & \\
\hline D14Mit54 & $14: 12.5$ & & & & -0.67 & \\
\hline Glud & $14: 15.5$ & & $+0.61[16]$ & & & Glud (15.5) \\
\hline Mtv11 & $14: 16$ & $-0.58[16]$ & & & & \\
\hline Ms15-7 & $14: 16.5$ & $-0.57[8]$ & & & & \\
\hline Gnrh & $14: 39.5$ & $-0.61[8] /-0.62[16]$ & & & & Gnrh (39.5) \\
\hline Es10 & 14:41 & & & & -0.64 & \\
\hline D15Mit7 & $15: 14.5$ & $+0.61[16]$ & & & & \\
\hline D15Mit1 & $15: 47.5$ & $+0.52[16]$ & & & & \\
\hline Spt1 & $15: 58.1$ & $+0.56[8]$ & & & & \\
\hline Comt & $16: 13$ & $+0.52[8]$ & & & & Comt/Drd3 (13.0/23.0) \\
\hline D16Mit70 & $16: 57$ & & $+0.51[16]$ & & & \\
\hline Zfp 40 & $17: 10.05$ & & $-\mathbf{0 . 6 7}[16]$ & & & \\
\hline D17Mit3 & $17: 41.5$ & $+0.58[16]$ & & & & \\
\hline Hprt-ps1 & $17: 47.6$ & & & -0.53 & +0.52 & Hprt-ps1 (47.6) \\
\hline Gnblps1 & 19:0 & & $-0.54[16]$ & & & Adra2a $(50.0)$ \\
\hline Lybp2 & $19: 2$ & & $-0.62[4]$ & & & Adrb1 (51.0) \\
\hline Pomc-2 & $19: 9$ & & $-0.65[8]$ & & & \\
\hline Lpc1 & $19: 18$ & & $-0.50[16]$ & & & \\
\hline DXNcvs10 & $20: 38.3$ & & & +0.66 & & \\
\hline
\end{tabular}

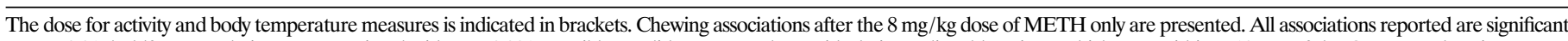
at $p \leq 0.01$; boldface correlations are associated with $p \leq 0.001$. Possible candidate genes, along with their predicted locations, which map within $\sim 10 \mathrm{cM}$ of the QTL, are also given. 

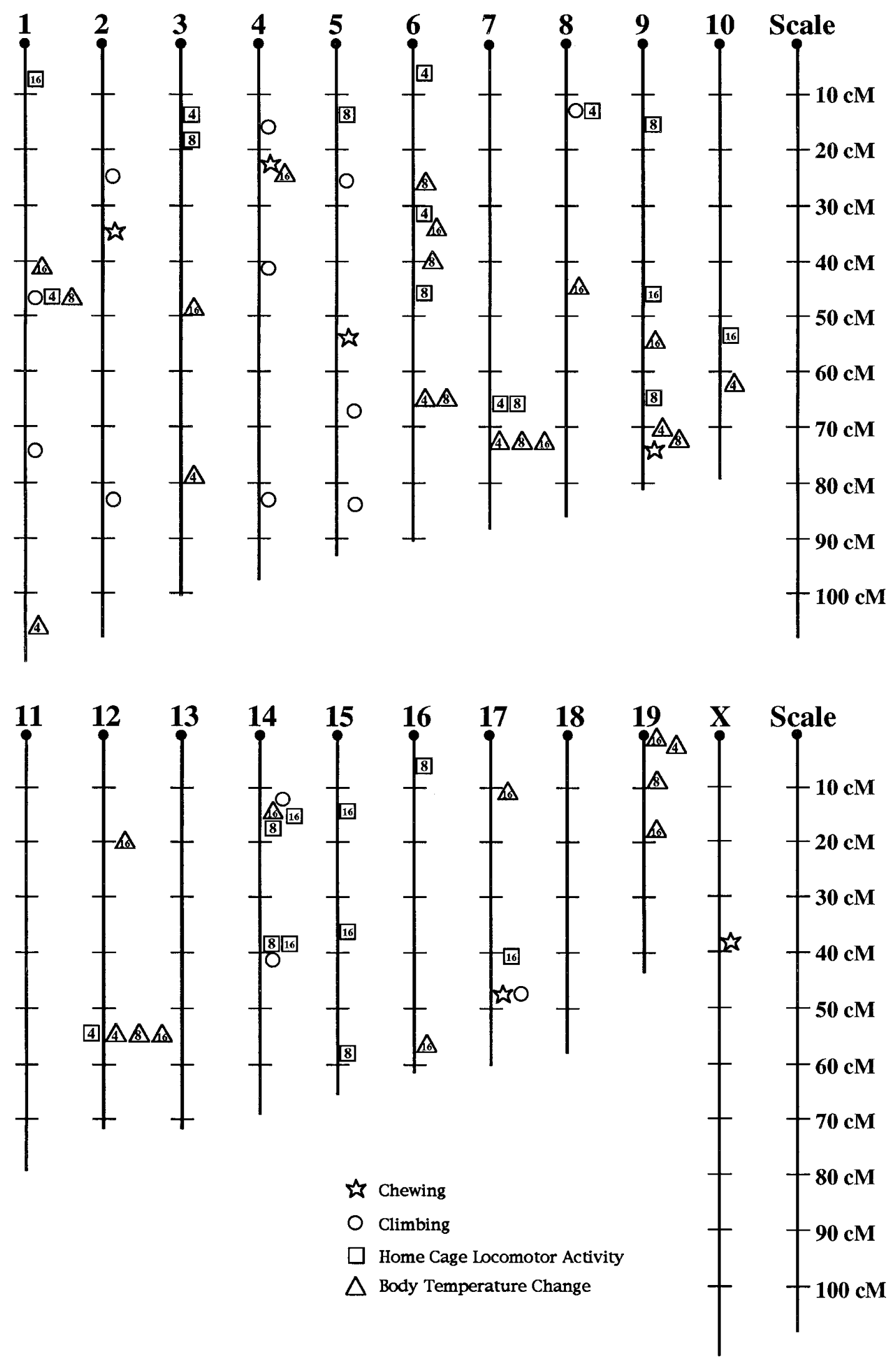

Figure 6. Schematic representation of genomic locations for putative QTLs underlying response to METH in the BXD RI strains and their progenitors. The 19 mouse chromosomes and the X chromosome are depicted proportionately; scale gives centimorgans (cM) from the centromere. For home cage activity (squares) and temperature changes (triangles), dose ( $\mathrm{mg} / \mathrm{kg}$ ) is indicated by number inside the symbol. Markers from Silver et al. (1994). 
found QTLs for METH's temperature effects in common with Gora-Maslak et al. (1991) only in the region from 27 to $31 \mathrm{cM}$ on chromosome 6. Recently, Tolliver et al. (1994) and Miner and Marley (1995) mapped QTLs contributing to the locomotor activation in the BXD RIs after cocaine administration. Tolliver and colleagues evaluated the response to $32 \mathrm{mg} / \mathrm{kg}$ cocaine in 16 strains, while Miner and Marley examined locomotor stimulation to $10 \mathrm{mg} / \mathrm{kg}$ cocaine in 11 of the BXDs. Both Tolliver et al. (1994) and Miner and Marley (1995) identified the region of chromosome 9 associated with the locomotor response that overlaps with the large cluster of QTLs that we found associated with several responses to METH on the distal portion of this chromosome (discussed above). All three studies also found a common region of influence near the D17 Mit3 and Hprt-ps1 loci on chromosome 17. As gene mapping studies of drug effects begin to accumulate, both discrepancies and commonalties between studies are potentially informative. The fact that common regions are found in studies of phenotypes that differ substantially (large dose ranges or different pharmacological agents) can lead to hypotheses about common mechanisms (see, for example, Crabbe et al., 1994). The Hprt-ps1 marker locus on chromosome 17, for instance, was associated with psychostimulant response in all of these studies. This is a pseudogene for the enzyme hypoxanthine-guanine phosphoribosyltransferase (HPRT) and, therefore, does not appear to translate any functional proteins (Isamat et al., 1988). It is interesting, however, that an HPRT enzyme deficiency is associated with the motor disorder Lesch-Nyhan syndrome in humans and with alterations in dopaminergic activity in motor nuclei and increased sensitivity to amphetamine-induced locomotion and stereotypy in mice (Jinnah et al., 1991, 1994), suggesting the possibility that polymorphisms in the retroposed HPRT pseudogene may differentially regulate (as endogenous antisense nucleotides) the HPRT gene itself (see, for example, Zhou et al., 1992; Akagi et al., 1994; Carlton et al., 1994; Manjanatha et al., 1994; Kas et al., 1995; Leedman et al., 1995).

A lack of concurrence between QTLs for different markers may be indicative of distinct genetic underpinnings for the different yet related phenotypes, or they may be attributable to other factors. It is possible, for instance, that more pleiotropic QTLs would have been identified in common if the same sex were tested for all phenotypes; as it happens, female mice were analyzed in the climbing study, whereas male mice were used to evaluate all other phenotypes. In a recent study by Melo et al. (1996) aimed at mapping genes associated with alcohol preference, two sexspecific QTLs were identified. Because these are the first genderspecific QTLs proposed for a pharmacological response, the prevalence of such sex-constrained loci is not yet known. However, many behavioral responses are known to vary significantly between females and males and, therefore, attempts at elucidating genetic substrates of such phenotypes should give this possibility serious consideration.

One of the ubiquitous effects of addictive drugs is behavioral stimulation (see Crabbe and Harris, 1991). This increased activity seen in both animals and humans after drug administration may reflect aspects of the reinforcing or rewarding effects of these drugs (Wise, 1978, 1987). The current use of QTL mapping in RI strains offers promise toward the identification of genes associated with locomotor activation in response to psychotropic drugs. The present findings suggest putative QTLs that may contribute to differences in METH sensitivity between individuals. The next step is to attempt to confirm these provisional QTL associations in an $\mathrm{F}_{2}$ (or other) population. In this way, offspring from B6 and D2 parents are individually phenotyped and then genotyped at areas of the genome suggested to reflect influences of QTLs from this RI study. When the correlations between behavior and allelic variation are confirmed in such a genetically segregating population, the case for a significant influence of these loci is strengthened further. Finally, congenic mice, isogenic at all loci except for a small region bracketing a QTL in question, can be created, contributing further to our understanding of the influence of a particular locus or gene product on a complex phenotype. In the interim, pharmacological or anatomical interventions can be used to test the hypothesis generated by preliminary QTL analysis in RIs (such as the role of glutamate or acetylcholine for genetic sensitivity to psychostimulants). These convergent methods of testing are likely to further the goal of understanding the precise molecular products that influence responding to psychostimulants and, therefore, susceptibility to drug abuse.

\section{REFERENCES}

Albanese A, Gozzo S, Iacopino C, Altavista MC (1985) Strain-dependent variations in the number of forebrain cholinergic neurons. Brain Res 334:380-384.

Akagi H, Sakamoto M, Shinjyo C, Shimada H, Fujimura T (1994) A unique sequence located downstream from the rice mitochondrial atp6 may cause male sterility. Curr Genet 25:52-58.

Balsara JJ, Muley MP, Vaidya AS, Chandorkar AG (1981) Effects of baclofen on dopamine-dependent behaviors in mice. Psychopharmacology 75:396-399.

Belknap JK, Metten P, Helms ML, O’Toole LA, Angeli-Gade S, Crabbe JC, Phillips TJ (1993) Quantitative trait loci (QTL) applications to substances of abuse: physical dependence studies with nitrous oxide and ethanol in BXD mice. Behav Genet 23:213-222.

Belknap JK, Mitchell SR, O’Toole LA, Helms ML, Crabbe JC (1996a) Type I and type II error rates for quantitative trait loci (QTL) mapping studies using recombinant inbred mouse strains. Behav Genet 26:149-160.

Belknap JK, Dubay C, Crabbe JC, Buck KJ (1996b) Mapping quantitative trait loci for behavioral traits in the mouse. In: Handbook of psychiatric genetics (Blum K, Noble E, eds), Ch 25. Boca Raton, FL: CRC.

Berettini WH, Ferraro TN, Alexander RC, Buchberg AM, Vogel WH (1994) Quantitative trait loci mapping of three loci controlling morphine preference using inbred mouse strains. Nature Genet 7:54-58.

Broadhurst PL (1978) Drugs and the inheritance of behaviour. New York: Plenum.

Cabib S, Zocchi A, Puglisi-Allegra S (1995) A comparison of the behavioral effects of minaprine, amphetamine and stress. Psychopharmacology 121:73-80.

Carlton MB, Colledge WH, Evans MJ (1995) Generation of a pseudogene during retroviral infection. Mamm Genet 6:90-95.

Copeland NG, Jenkins NA, Gilbert DJ, Eppig JT, Maltais LJ, Miller JC, Dietrich WF, Weaver A, Lincoln SE, Steen RG, Stein LD, Nadeau JH, Lander ES (1993) A genetic linkage map of the mouse: current applications and future prospects. Science 262:57-66.

Crabbe JC (1986) Genetic differences in locomotor activation in mice. Pharmacol Biochem Behav 25:289-292.

Crabbe JC, Belknap JK (1993) Behavior genetic analyses of drug withdrawal. Alcohol Alcoholism Suppl 2:477-482.

Crabbe JC, Harris RA (Eds) (1991) The genetic basis of alcohol and drug actions. New York: Plenum.

Crabbe JC, Belknap JK, Buck KJ (1994) Genetic animal models of alcohol and drug abuse. Science 264:1715-1723.

Dains KM (1995) Genetics and the organization of cholinergic neurons in the mouse caudate-putamen. PhD dissertation, SUNY v.

de Wit H, Uhlenhuth EH, Johanson CE (1986) Individual differences in the reinforcing and subjective effects of amphetamine and diazepam. Drug Alcohol Depend 16:341-60.

Durkin T, Ayad G, Ebel A, Mandel P (1977) Regional acetylcholine turnover rates in the brains of three inbred strains of mice: correlation with some interstrain behavioral differences. Brain Res 136:475-486.

Ebel A, Hermetet JC, Mandel P (1973) Comparative study of acetylcholinesterase and choline acetyltransferase enzyme activity in brains of DBA and C57 mice. Nature New Biol 242:56-58. 
Florin SM, Kuczenski R, Segal DS (1992) Amphetamine-induced changes in behavior and caudate extracellular acetylcholine. Brain Res 581:53-58.

Gora-Maslak G, McClearn GE, Crabbe JC, Phillips TJ, Belknap JK, Plomin R (1991) Use of recombinant inbred strains to identify quantitative trait loci in psychopharmacology. Psychopharmacology 104:413-424.

Graybiel AM (1990) Neurotransmitters and neuromodulators in the basal ganglia. Trends Neurosci 13:241-244.

Groves PM, Rebec GV (1976) Biochemistry and behavior: some central actions of amphetamine and antipsychotic drugs. Annu Rev Psychol 27:91-127.

Groves PM, Garcia-Munoz M, Linder JC, Manley MS, Martone MM, Young SJ (1995) Elements of the intrinsic organization and information processing in the neostriatum. In: Models of information processing in the basal ganglia (Houk JC, Davis JL, Beiser DG, eds), pp 51-96. Cambridge MA: MIT.

Hegmann JP, Possidente B (1981) Estimating genetic correlations from inbred strains. Behav Genet 11:103-114.

Hernandez L, Lee F, Hoebel BG (1987) Simultaneous microdialysis and amphetamine infusion in the nucleus accumbens and striatum of freely moving rats: increase in extracellular dopamine and serotonin. Brain Res Bull 19:623-628.

Iacopino C, Altavista MC, Gozzo S, Albanese A (1986) Qualitative pharmacohistochemistry of acetylcholinesterase in the neostriatum of inbred mouse strains. Brain Res 374:402-408.

Isamat M, Macleod KF, King A, McEwan C, Melton DW (1988) Characterization, evolutionary relationships and chromosome location of processed mouse HPRT pseudogene. Cell Mol Genet 14:359-369.

Jaworska-Feil L, Budziszewska B, Lason W (1995) The effects of repeated amphetamine administration on the thyrotropin-releasing hormone level: its release and receptors in the rat brain. Neuropeptides 29:171-176.

Jellinek P (1971) Dual effect of dexamphetamine on body temperature in the rat. Eur J Pharmacol 15:389-392.

Jinnah HA, Gage FH, Friedmann T (1991) Amphetamine-induced behavioral phenotype in a hyposanthine-guanine phosphoribosyltransferase-deficient mouse model of Lesch-Nyhan syndrome. Behav Neurosci 105:1004-1012.

Joshi VV, Balsara JJ, Jadhav JH, Chandorkar AG (1981) Effect of L-histidine and chlorcyclizine on apomorphine-induced climbing behaviour and methamphetamine stereotypy in mice. Eur J Pharmacol 69:499-502.

Karler R, Calder LD, Thai LH, Bedingfield JB (1994) The dopaminergicglutamatergic, basis for the action of amphetamine and cocaine. Brain Res 658:8-14.

Karler R, Calder LD, Thai LH, Bedingfield JB (1995) The dopaminergic, glutamatergic, GABAergic bases for the action of amphetamine and cocaine. Brain Res 671:100-104.

Kas K, Stickens D, Merregaert J (1995) Characterization of a processed pseudogene of human FAU1 on chromosome 18. Gene 160:273-276.

Kitahama K, Valatx J-L (1979) Strain differences in amphetamine sensitivity in mice. I. A diallel analysis of open field activity. Psychopharmacology 66:189-194.

Kuczenski R (1986) Dose response for amphetamine-induced changes in dopamine levels in push-pull perfusates of rat striatum. J Neurochem 46:1605-1611.

Kuczenski R, Segal DS (1989) Concomitant characterization of behavioral and striatal neurotransmitter response to amphetamine using in vivo microdialysis. J Neurosci 9:2051-2065.

Kuczenski R, Segal DS (1990) In vivo measures of monoamines during amphetamine-induced behaviors in rats. Prog Neuropsychopharmacol Biol Psychiatry 14:S37-S50.

Kuczenski R, Schmidt D, Leith N (1977) Amphetamine-haloperidol interactions in rat striatum: failure to correlate behavioral effects with dopaminergic and cholinergic dynamics. Brain Res 126:117-129.
Kuczenski R, Segal DS, Aizenstein ML (1991) Amphetamine, cocaine and fencamfamine: relationship between locomotor and stereotypy response profiles and caudate and accumbens dopamine dynamics. J Neurosci 11:2703-2712.

Lander E, Kruglyak L (1995) Genetic dissection of complex traits: guidelines for interpreting and reporting linkage results. Nature Genet 11:241-247.

Leedman PJ, Stein AR, Chin WW (1995) Regulated specific protein binding to a conserved region of the 3 '-untranslated region of thyrotropin $\beta$-subunit mRNA. Mol Endocrinol 9:375-387.

Li WH, Graur D (1991) Fundamentals of molecular evolution. Sunderland, MA: Sinauer.

Liljequist S, Karcz-Kubicha M (1993) Genetic aspects on the effects of ethanol and central stimulants on locomotor activity and brain dopamine metabolism in mice. Alcohol Alcoholism Suppl 2:457-461.

Manjanatha MG, Lindsey LA, Mittelstaedt RA, Heflich RH (1994) Low hprt mRNA levels and multiple hprt mRNA species in 6-thioguanineresistant Chinese hamster cell mutants possessing nonsense mutations. Mutation Res 308:65-75.

Marcais H, Protais P, Costentin J, Schwartz JC (1978) A gradual score to evaluate the climbing behaviour elicited by apomorphine in mice. Psychopharmacology 56:233-234.

Melo JA, Shendure J, Pociask K, Silver LM (1996) Identification of sex-specific quantitative trait loci controlling alcohol preference in C57BL/6 mice. Nature Genet 13:147-153.

Miner LL, Marley RJ (1995) Chromosomal mapping of the psychomotor stimulant effects of cocaine in BXD recombinant inbred mice. Psychopharmacology 122:209-214.

Phillips TJ, Crabbe JC, Metten P, Belknap JK Localization of genes affecting alcohol drinking in mice. Alcohol Clin Exp Res 18:931-941.

Protais P, Costentin J, Schwartz JC (1976) Climbing behavior induced by apomorphine in mice: a simple test for the study of dopamine receptors in striatum. Psychopharmacology 50:1-6.

Randrup A, Munkvad I (1967) Stereotyped activities produce by amphetamine in several animal species and man. Psychopharmacologia 11:300-310.

Randrup A, Munkvad I, Fog R, Ayhan IH (1975) Catecholamines in activation, stereotypy, and level of mood. In: Catecholamines and behavior, Vol 1 (Friedhoff AJ, ed), pp 89-107. New York: Plenum.

Rodriguez LA, Plomin R, Blizard DA, Jones BC, McClearn GE (1995) Alcohol acceptance, preference, and sensitivity in mice. II. Quantitative trait loci mapping analysis using BXD recombinant inbred strains. Alcohol Clin Exp Res 19:367-373.

Schwab C, Bruckner G, Castellano C, Oliverio A, Biesold D (1990) Regional cholinergic differences in the brains of DBA/2 and C57BL/6 mice: a morphological study during ontogeny. Dementia 1:74-78.

Seale TW (1991) Genetic differences in response to cocaine and stimulant drugs. In: The genetic basis of alcohol and drug actions (Crabbe JC, Harris RA, eds), pp 279-321. New York: Plenum.

Seale TW, Carney JM, Johnson P, Rennert OM (1985) Inheritance of amphetamine-induced thermoregulatory responses in inbred mice. Pharmacol Biochem Behav 23:373-377.

Silver LM, Nadeau JH, Goodfellow PN, editors (1994) Mamm Genome 5 .

Tolliver BK, Belknap JK, Woods WE, Carney JM (1994) Genetic analysis of sensitization and tolerance to cocaine. J Pharmacol Exp Ther 270:1230-1238.

Wise RA (1978) Catecholamine theories of reward: a critical review. Brain Res 152:215-217.

Wise RA (1987) The role of reward pathways in the development of drug dependence. Pharmacol Ther 35:227-263.

Zhou BS, Beidler DR, Cheng YC (1992) Identification of antisense RNA transcripts from a human DNA topoisomerase I pseudogene. Cancer Res 52:4280-4285. 